\title{
Analysis on Interfacial Performance of CFRP- Concrete with Different Thickness of Adhesive Layer and CFRP Plate
}

\author{
Qingyong $\mathrm{Guo}^{1}{ }^{*}$, Huijian Zhao ${ }^{1}$, Lei Chen ${ }^{1}$, Jize Mao ${ }^{1}$, and Wensong Zhang ${ }^{2}$ \\ ${ }^{1}$ College of Aerospace and Civil Engineering, Harbin Engineering University,Harbin 150001, China \\ ${ }^{2}$ General Research Institute for Nonferrous Metals, Beijing 100088, China
}

\begin{abstract}
The bond behavior of CFRP-concrete interface is the analysis foundation for concrete structures with external strengthening CFRP. In the paper, the influences of the thickness of CFRP plate and adhesive layer on interfacial adhesive properties are investigated through the finite element program. The influence rules of the thickness on the interfacial ultimate bearing capacity and the effective bond length are performed.The results show that the thickness of adhesive layer and CFRP plate has a significant effect on the interfacial performance of CFRP-concrete.
\end{abstract}

\section{Introduction}

In recent years, the strengthening of building structure has become the focus of attention. At present, the commonly used reinforcement methods are increasing the old section method, cladding steel method, carbon fiber (Carbon Fiber, Reinforced, Polymer, referred to as CFRP) reinforcement method. Carbon fiber reinforcement has attracted wide attention due to its superior tensile and durability properties. Therefore, the study on interfacial properties of CFRP-concrete plays an important role in analysis on the performance of CFRP reinforced concrete structures.

At present, researchers in China and abroad have made a great deal of studies on the interfacial performance of CFRP and concrete [1]. It is shown that the thickness of CFRP plate and interface adhesive layer have great influences on the interfacial bond behavior of CFRP-concrete. Otherwise, there arefew researches focus on the effects of the thickness of interface adhesive layer on bonding properties for CFRP- concrete. Peng Hui etc. concluded that the increase of the adhesive layer thickness reduced the fatigue damage, and the ultimate bearing capacity also increased [2]. Ma Tao etc. carried out single shear test finding that the initial peel load increases with the thicker adhesive layer[3].It is found that the layer thickness is one of the most important parameters for interfacial adhesive properties of CFRP and concrete, and there are differences among existing conclusions. As a result, there is need to do further study on it. The paper studies the influences of the thickness of CFRP plate and adhesive layer on interfacial adhesive properties by dint of the numerical analysis. The influence rules of the thickness on the interfacial ultimate bearing

\footnotetext{
* Corresponding author: qingyong622@126.com
} 
capacity and the effective bond length are performed. Some conclusions have been drawn finally.

\section{Constitutive model of materials}

\subsection{Plastic damage constitutive model of concrete}

The plastic damage model of ABAQUS is used for concrete. The model is based on the Lubliner[4] and Lee and Fenves[5] models. The model expresses the inelastic behavior of concrete materials using an isotropic damage elasticity combined with an isotropic tensile and compressive plastic model. The model considers the degradation of elastic tensile and compression stiffness strain caused by plastic strain. It can simulate the mechanical properties of concrete, such as crushing and tension fracture, and is a plastic model based on continuous medium[6].

\subsection{Constitutive model of interface element}

Based on the analysis of nonlinear fracture mechanics, it can be seen that the bearing capacity of CFRP- concrete interface is related to the fracture energy of interface, and it is independent of the shape of bond slip curve[7]. Because the bilinear model is simple in form, it is easy to be used in finite element simulation. The bilinear model has three important parameters, namely, the initial shear stiffness of interface $\left(K_{0}\right)$, the maximum shear stress at interface $\left(\tau_{\max }\right)$ and the interfacial fracture energy $\left(G_{f}\right)$.

Interfacial initial shear stiffness can be expressed as

$$
K_{0}=\frac{\tau_{\max }}{s_{0}}
$$

Where, $s_{0}$ is the corresponding relative slip of the maximum shear stress.

Interfacial fracture energy can be expressed as

$$
G_{f}=\frac{1}{2} \tau_{\max } s_{f}
$$

Where, $s_{f}$ is the maximum slip of the interface.

\subsection{The interface bond slip model}

Many researchers obtained different interface bond slip models through experimental study. Here Ueda et al. modelis adopted for simulation which considers more factors. It is expressed as follows,

$$
\begin{gathered}
\tau=2 B G_{f}\left(e^{-B s}-e^{-2 B s}\right) \\
\tau_{\max }=0.5 B G_{f} \\
s_{0}=\frac{0.693}{B}
\end{gathered}
$$




$$
\begin{gathered}
B=6.846\left(E_{f} t_{f}\right)^{0.108}\left(G_{a} / t_{a} / 1000\right)^{0.833} \\
G_{f}=0.446\left(E_{f} t_{f}\right)^{0.023}\left(G_{a} / t_{a} / 1000\right)^{-0.352} f_{c}^{0.236}
\end{gathered}
$$

Where, $E_{f}$ is the elastic modulus of the FRP plate, $t_{f}$ is the thickness of the CFRP plate, and $G_{a}$ is the shear modulus of the adhesive layer, and $t_{a}$ is the thickness of the adhesive layer, $\mathrm{s}$ is the local slip, $f_{c}$ is the compressive strength of concrete.

\section{Finite element model}

At present, the methods to analyze the interface performance of CFRP-concrete by using finite element software can mainly be classified into two kinds. One is to divide concrete and CFRP into the same size units in the process of building the finite element model. Common nodes are used to establish a connection between the concrete and CFRP board, where the appropriate constitutive model of concrete is selected. The process of CFRPconcrete interfacial debonding is reflected by the cracking ofconcrete on the interface.

The second method is to transform the nonlinear problem of concrete cracking at the interface into the failure of the interface element. It not only saves the computing cost, but also will consider the effect of adhesive thickness on the interfacial properties of CFRPconcrete. Therefore, the paper introduces the method of introducing special interface unit between CFRP plate and concrete. Fig. 1 is the geometrical size and load position of the model.

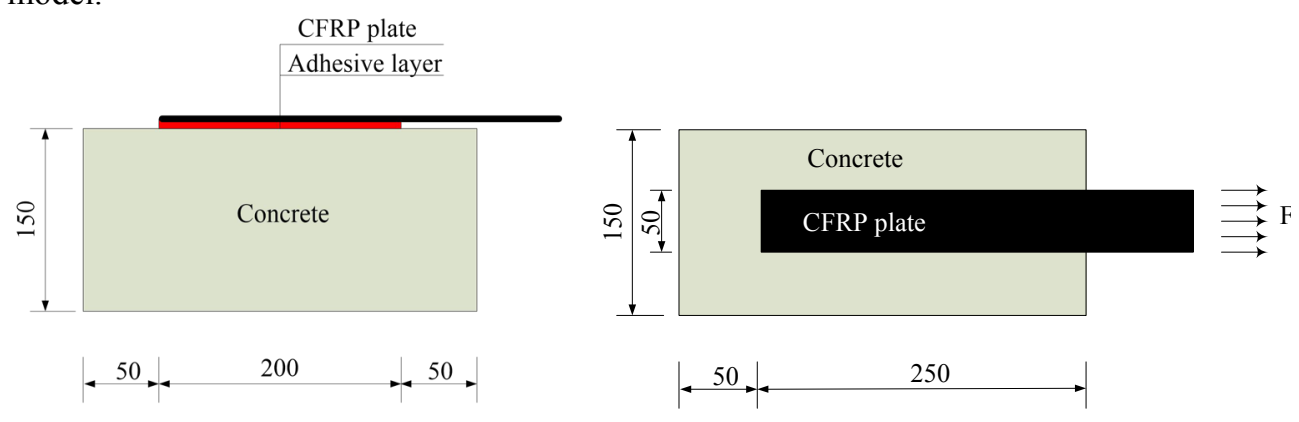

Fig. 1. FRP-to-concrete bonded joints model

Table 1. Material performance index ${ }^{[8]}$

\begin{tabular}{|c|c|c|}
\hline Material & Project & Parameter \\
\hline \multirow{3}{*}{ CFRP plate } & Elastic modulus & $165000 \mathrm{MPa}$ \\
\cline { 2 - 3 } & Tensile strength & $2461 \mathrm{MPa}$ \\
\cline { 2 - 3 } & Elongation & $1.71 \%$ \\
\hline \multirow{3}{*}{ Epoxy resin } & Elastic modulus & $2627 \mathrm{MPa}$ \\
\cline { 2 - 3 } & Tensile strength & $31.7 \mathrm{MPa}$ \\
\cline { 2 - 3 } & Elongation & $1.5 \%$ \\
\hline Concrete & Strength & $38.5 \mathrm{MPa}$ \\
\hline
\end{tabular}

The width, height and length of the concrete specimen are $150 \mathrm{~mm}, 150 \mathrm{~mm}$ and $300 \mathrm{~mm}$ separately. The width of CFRP plate is $50 \mathrm{~mm}$, the bond length is $200 \mathrm{~mm}$, and the 
loading end has $50 \mathrm{~mm}$ from nonbonding zone. In the paper, the concrete model is made of solid element, and the element type is chosen as the C3D8R unit with 3D eight nodes which are reduced integration element. In the entire model from stress to failure, CFRP are in the small strain condition. For convergence and convenience of the model, the CFRP plate can regard as a linear elastic material. It does not distinguish between fiber and resin, and uses the equivalent elastic modulus for modeling. The adhesive layer takes COH3D8 unit as cohesive element with 3D eight nodes. The material parameters which are used for the model are shown in table 1. Parameters of specimen and ultimate bearing capacity calculated are shown in table 2.

Table 2. Parameters of specimens and numerical ultimate bearing capacity

\begin{tabular}{|c|c|c|c|c|c|c|}
\hline $\begin{array}{c}\text { Specimen } \\
\text { number }\end{array}$ & $\begin{array}{c}\text { CFRP plate } \\
\text { thickness } \\
(\mathrm{mm})\end{array}$ & $\begin{array}{c}\text { Adhesive } \\
\text { layer } \\
\text { thickness } \\
(\mathrm{mm})\end{array}$ & $\begin{array}{c}\text { Interface } \\
\text { initial } \\
\text { stiffness } \\
(\mathrm{MPa} / \mathrm{mm})\end{array}$ & $\begin{array}{c}\text { Maximum } \\
\text { shear stress } \\
(\mathrm{MPa})\end{array}$ & $\begin{array}{c}\text { Interfacial } \\
\text { failure } \\
\text { energy } \\
(\mathrm{J})\end{array}$ & $\begin{array}{c}\text { Numerical } \\
\text { ultimate } \\
\text { bearing } \\
\text { capacity(kN) }\end{array}$ \\
\hline F1-1 & 1 & 1 & 119.71 & 6.69 & 1080 & 33.55 \\
\hline F1-2 & 1 & 2 & 48.15 & 4.80 & 1378 & 34.22 \\
\hline F1-3 & 1 & 3 & 28.26 & 3.95 & 1590 & 32.67 \\
\hline F1-4 & 1 & 4 & 19.37 & 3.44 & 1759 & 29.88 \\
\hline F1.4-1 & 1.2 & 1 & 129.74 & 6.99 & 1088 & 39.11 \\
\hline F1.4-2 & 1.2 & 2 & 52.18 & 5.01 & 1389 & 39.09 \\
\hline F1.4-3 & 1.2 & 3 & 30.63 & 4.12 & 1602 & 35.98 \\
\hline F1.4-4 & 1.2 & 4 & 20.99 & 3.59 & 1773 & 32.45 \\
\hline F2-1 & 2 & 1 & 141.28 & 7.33 & 1097 & 46.66 \\
\hline F2-2 & 2 & 2 & 56.83 & 5.25 & 1400 & 44.50 \\
\hline F2-3 & 2 & 3 & 33.35 & 4.32 & 1615 & 39.43 \\
\hline F2-4 & 2 & 4 & 22.86 & 3.76 & 1787 & 34.80 \\
\hline
\end{tabular}

\section{Results analysis and discussion}

\subsection{Analysis of ultimate bearing capacity}

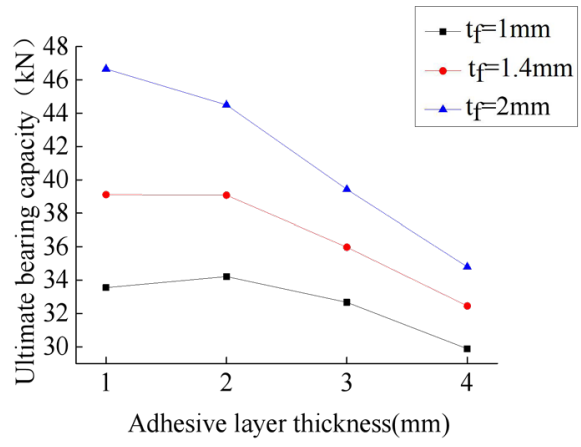

(a)

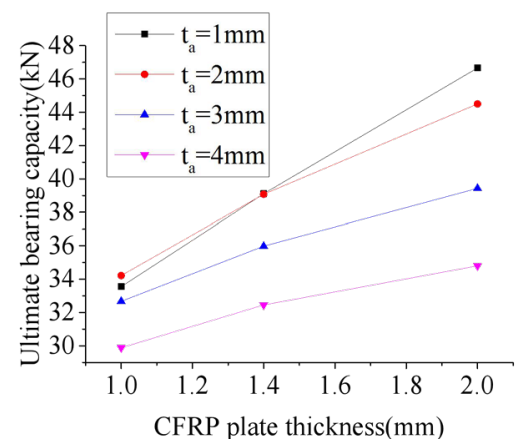

(b) 


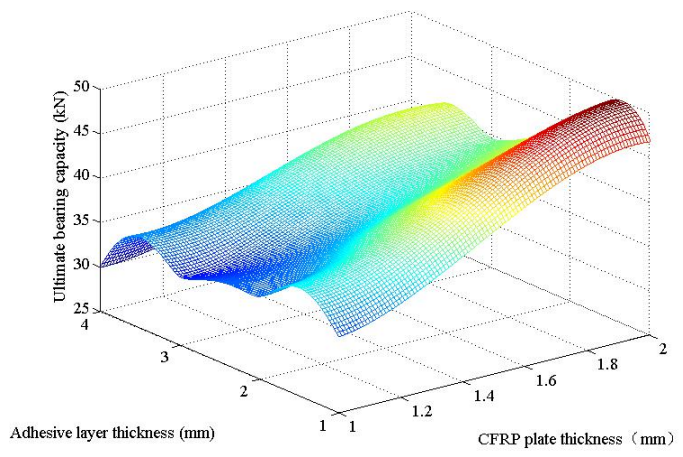

(c)

Fig. 2. Ultimate bearing capacity of interface with different thickness of adhesive layer and CFRP

In Fig. 2 and table 2, it is shown that the thickness of the adhesive layer and CFRP plate have a great influence on the interfacial ultimate bearing capacity. The ultimate bearing capacity of the interface increases generally as the thickness of the adhesive layer decreases and as the thickness of the CFRP plate increases.Fig. 2(a) shows that the ultimate bearing capacity of $1 \mathrm{~mm}$ CFRP plate increases firstly and then decreases with the increase of the adhesive layer thickness, and reaches the maximum around $2.0 \mathrm{~mm}$. However, it is almost flat for $1.4 \mathrm{~mm}$ CFRP plate and goes down for 2.0mm CFRP plate.

Fig. 2 (b) shows that the ultimate bearing capacity increases with the increase of the plate thickness. When the adhesive layer thickness is $1 \mathrm{~mm}$ and $2 \mathrm{~mm}$, the interfacial ultimate bearing capacity increases with the increase of the plate thickness, which is obviously greater than that of the adhesive layer at $3 \mathrm{~mm}$ and $4 \mathrm{~mm}$. Its maximum value can be obtained when the plate thickness is around $2.0 \mathrm{~mm}$ and adhesive layer thickness is around $1.5 \mathrm{~mm}$ as shown in Fig. 2 (c).

\subsection{Distribution of strain in CFRP plates and adhesive layers}

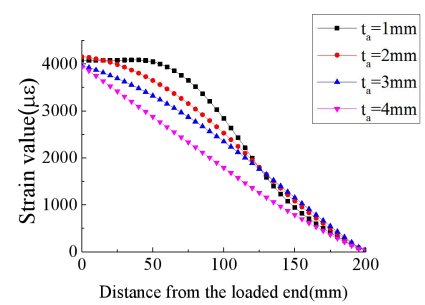

(a) $\mathrm{t}_{\mathrm{a}}=1 \mathrm{~mm}$

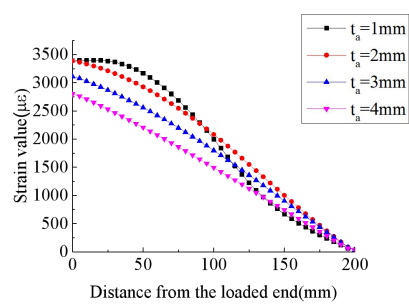

(b) $\mathrm{t}_{\mathrm{a}}=1.4 \mathrm{~mm}$

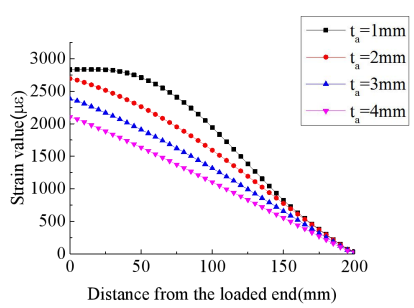

(c) $t_{a}=2 \mathrm{~mm}$

Fig.3. Strain distribution in CFRP plates

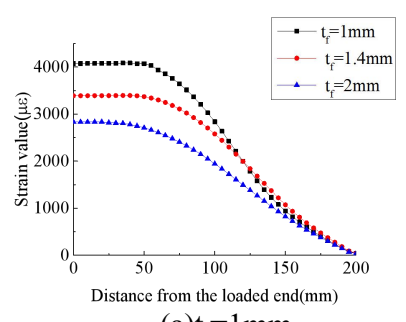

(a) $\mathrm{t}_{\mathrm{f}}=1 \mathrm{~mm}$

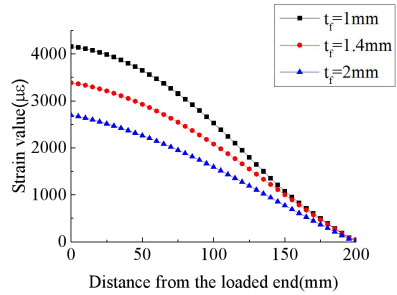

(b) $t_{\mathrm{f}}=2 \mathrm{~mm}$

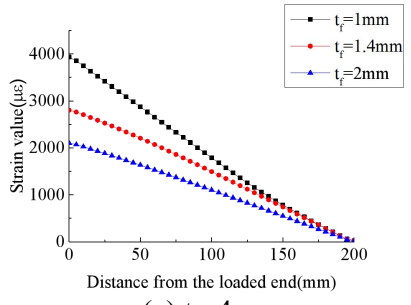

(c) $\mathrm{t}_{\mathrm{f}}=4 \mathrm{~mm}$

Fig.4. Strain distribution in adhesive layers 
Fig. 3 exhibits the variation of strain values on the CFRP plate with ultimate bearing capacity. It is demonstrates that the maximum strain in the plates decrease as the thickness of plate increases.Fig. 3(a) shows that the maximum strain of the four specimens has little difference when the thickness of the CFRP plate is $1 \mathrm{~mm}$. The flat segments on the strain curve mean that the bond length of the two specimens is greater than the effective bond length when $\mathrm{tf}=1 \mathrm{~mm}$ and $\mathrm{tf}=2 \mathrm{~mm}$. It explains why the trend of the interfacial ultimate bearing capacity goes flatly when $t f \leq 2 \mathrm{~mm}$. In Fig.3(c), the maximum strain of the four curves decreases with the increase of the adhesive layer, and only the curve with the adhesive layer of $1 \mathrm{~mm}$ has a horizontal section. The above results show that the increase of the adhesive layer thickness leads to the increase of the interfacial effective bond length.

Fig. 4 gives the strain distribution of the CFRP plates with different thickness. The lengths of flat segment are $50 \mathrm{~mm}, 45 \mathrm{~mm}$ and $30 \mathrm{~mm}$ for ta $=1 \mathrm{~mm}, \mathrm{ta}=1.2 \mathrm{~mm}$ and ta $=1.4 \mathrm{~mm}$ respectively shown in Fig. 4(a). It indicates that the effective bond lengths of the three specimens are $150 \mathrm{~mm}, 155 \mathrm{~mm}$ and $170 \mathrm{~mm}$ respectively when $\mathrm{tf}=1 \mathrm{~mm}$. Fig. 4 (b) and Fig. 4(c) show that lengths of the flat segments become short and disappear finally. It is found that the effective bond length increases with the increase of plate thickness. This corresponds to the trend of the curve in Fig. 2.

\section{Summary}

In the paper, the numerical analysis had been carried out on interfacial performance of CFRP-concrete with the CFRP plate thickness $1 \mathrm{~mm}, 1.4 \mathrm{~mm}, 2 \mathrm{~mm}$ and adhesive thickness $1 \mathrm{~mm}, 2 \mathrm{~mm}, 3 \mathrm{~mm}$ and $4 \mathrm{~mm}$, the following conclusions are obtained:

1)The thicknesses of adhesive layer and CFRP plate have a significant effect on the interfacialperformance of CFRP-concrete.

2)The ultimate bearing capacity of the interface increases generally as the thickness of the adhesive layer decreases and as the thickness of the CFRP plate increases. Its maximum value can be obtained when the plate thickness is around $2.0 \mathrm{~mm}$ and adhesive layer thickness is around $1.5 \mathrm{~mm}$

3)The increase of the thickness of adhesive layer and CFRP plate leads to the increase of the interfacial effective bond length evidently.

This research was financially supported by Natural Science Foundation of Heilongjiang Province of China(NO:E201415) and the Fundamental Research Funds for the Central Universities of China (No.GK2020260143).

\section{References}

1. Guo Zhanggen, Sun Weimin, Zhen Zhen. Journal of Nanjing University of Technology (Family Science Edition). 28,37 (2006)

2. Peng Hui, Gao Yong, Xie Chao, et al. Experimental mechanics. 29,489 (2014)

3. Ma Tao, Pan Jinlong, Wei Hongli. Building Structure. 19,15 (2013)

4. Lubliner J, Oliver J, Oller S, et al. International Journal of Solids and Structures. 25,299 (1989)

5. Lee J, Fenves G L. Journal of Engineering Mechanics. 124,892 (1998)

6. ABAQUS analysis user's manual v6.14 (ABAQUSInc, 2014)

7. Täljsten B. Springer (2014)

8. Peng Hui, Gao Yong, Xie Chao, et al. Experimental mechanics. 29,489 (2014) 